\title{
Experience of indian army's aeromedical evacuation of casualities
}

\section{Evacuaciones aeromédicas, experiencia de la India}

\author{
Shibu Sasidharan MD, DNB, MNAMS. 1,*, Sophie Montagnon², Rohit Kapur MBBS. ${ }^{3}$, Harpreet Singh Dhillon MD. ${ }^{4}$ \\ (Anaesthesia); Team Leader; Dept of Anaesthesia and Critical care, Level III UN Hospital, Goma. \\ 2 Senior Medical Officer, UN Medical Emergency Response Team (UNMERT), Division of Healthcare Management and Occupa- \\ tional Safety and Health (DHMOSH), Office of Support Operations, Department of Operational Support, United Nations, New \\ York. \\ 3 Commanding Officer, Level III UN Hospital, Goma. \\ 4 Psychiatry, Level III UN Hospital, Goma.
}

Conflicting Interest (If present, give more details): NIL

Date of reception: 09 april 2021 / Date of acceptance: 12 june 2021

\begin{abstract}
Casualty Evacuation (CASEVAC) is not an end in itself but is a tool that makes possible more effective treatment. Pre-hospital care is crucial to patient outcomes, and effective care in this sphere will significantly reduce mortality. Ideally, treatment is continuing during evacuation. This article aims to review existing literature and experiences of emergency evacuation teams of the armed forces to give an insight on appropriate working principles and guidelines to the working staff involved in the air-medicalevacuation for its smooth execution. The article discusses addressing the medical care doctrines of 'Scoop-and-scoot' versus 'Stay-and-Play', the advantages and goals of timely CASEVAC, how to accord priority, what the stressors of flight are and the pathophysiology behind it, the anticipated problems in monitoring and evacuations; and checklists and recommendations for the same.
\end{abstract}

Key words: MEDEVAC, CASEVAC, evacuation of casualties, trauma care, emergency medicine.

\section{RESUMEN}

La evacuación de paciente crítico es una herramienta que permite optimizar el tratamiento. Idealmente el tratamiento debe ser continuo durante la evacuación y esto ha demostrado que mejora la morbimortalidad. En este artículo se revisan las principales indicaciones y guías para definir priorización, listas de chequeo y de monitorización.

Palabras clave: Evacuación de paciente crítico, heridas y lesiones, medicina de emergencia.

\section{Introduction}

$\mathrm{E}$ ver since organized trauma systems came into vogue, the importance of simultaneous rapid evaluation and management of immediately life-threatening injuries has been widely promulgated. One-half of injury deaths occur at the scene. In these patients, only prevention efforts might alter the outcome. Another $25 \%$ of deaths occur within the first 24 hours of hospitalization, principally due to massive haemorrhage or traumatic brain injury[1]. This potentially salvageable group might receive the greatest benefit from expeditious evaluation, timely evacuation, and further management.

The scenario is the same in war. By swift, short interval, high-intensity combat, the enemy can result in many casual- 
ties. This has encouraged armed forces and casualty evacuation teams worldwide to develop a highly efficient casualty air evacuation (CASEVAC) system that can surpass the standards of care accessible at field medical units and transport unstable patients with organ dysfunction[2].

For efficient CASEVAC, pre-hospital care is crucial to patient outcomes, and effective care in this sphere will significantly reduce mortality. Role 1 care in battlefield medicine is "unit-level medical care" that spans the point of injury (POI) through fixed battalion aid stations (BAS) that do not possess surgical capabilities-which further creates challenges as this encompasses a wide variety of tactical situations and levels of medical provider training (e.g., battlefield first responder through medical officer). Primary medical care is comprised of self-aid and buddyaid before potentially being followed by combat lifesaver care. Then, medically trained personnel - medics, physician assistants (PAs), and physicians - provide trauma management. Typically, combat medics accompany units on operations forward from tactical infrastructure, while PAs and physicians remain at the BAS. However, this is further complicated by special operation forces often conducting combat missions with medical officers near the combat.

In the theatres of war and at the point of trauma, addressing the medical care doctrines of 'Scoop-and-scoot' versus 'Stay-and-Play' is an ongoing debate. Stay and play is the approach of pre-hospital trauma care in which the patient receives treatment and stabilization on the scene before being transported to the hospital. Following medical interventions are distinctive for the stay and play approach: intubation on the scene to secure the airway, thoracostomy, placement of intravenous lines and starting the fluid resuscitation therapy, administration of medications on scene. Stay and Play is only helpful if we cannot get away or get the patient to a suitable hospital in time without detrimental deterioration. However, most importantly, who is staying, how they are playing, and their skills sets might have a tremendous influence on the outcome but are so poorly characterized that any definitive conclusions regarding efficacy are impossible.

Scoop and run is the approach of pre-hospital trauma care in which the patient is transported as fast as possible to the hospital without trying to stabilize him at the scene. The more advanced pre-hospital care methods used in the stay and play approach are not used. Although the theoretical advantages of pre-hospital ALS for injured patients appear to agree with some of the fundamental principles of trauma care, increasing evidence suggests that such interventions might have unanticipated harmful effects. The approach in Israel where they train bystanders and taxi drivers to rush to the hospital with a casualty would likely support the scoop and run. The distance from the appropriate hospital is a factor as well. Specifically, while early intervention appears to be vital to preventing deaths following significant trauma, many pre-hospital interventions do not provide definitive management of the injury, which constitutes the primary threat to survival - and unnecessary manoeuvres may, in fact, delay definitive management.

The latter approach would be "sweep and treat": do your things on the road/ in the air. There is ample experience from the UK MERT (air ambulance in Afghanistan) that for the very seriously injured, and en-route dedicated pre-hospital resuscitation team focused on stopping the bleeding and getting blood products in as early as possible, produced unexpected survivors. It was recorded that the transport, the forward resuscitation and the multiple operating teams in the receiving hospital achieved higher than expected survivor numbers.

An assigned mission of the armed forces, while operating at homeland or overseas on deputation to the overseas, is to provide aero-med transportation for the sick and wounded within the combat theatre. The chief objective of aero-med transportation is the expedient delivery of the casualty to the care level necessary for survival. The flexibility and rapid deployment of air services make this an optimal method of delivery. Aero-med transport involves the use of either fixed or rotor-wing aircraft. The capabilities of the medical air evacuation include:

a) the aeromedical evacuation of critically wounded or other patients.

b) extrication and then air evacuation of personnel from crashed aircraft.

c) emergency aid at air-crash sites, in-flight medical treatment, and surveillance of patients en-route to treatment facilities;

d) expeditious delivery of medical personnel and material to meet emergency treatment requirements within a combat zone. and

e) in-flight emergency medical care.

Evacuation is not an end in itself but, at a minimum, is a tool that makes possible more effective treatment. Timely med/cas evacuation simplifies the commander's combat service support mission. At the same time, by allowing the deployment of the most logistically demanding, immobile, and vulnerable medical assets far to the rear. Ideally, treatment is ongoing during evacuation[3]. This article aims to review existing literature and experiences of emergency evacuation teams of the armed forces to give an insight on appropriate working principles and guidelines to the working staff involved in the air-medical-evacuation for its smooth execution[4]. The ensuing paragraphs discuss the advantages and goals of timely CASEVAC, how to accord priority, the stressors of flight, the pathophysiology behind it, the anticipated problems in monitoring and evacuations, and checklists and recommendations for the same.

\section{Advantages}

Advantages of aeromedical medical evacuation (Table 2) include:

\section{Priority}

Assignment of Medical Evacuation Priority is of utmost importance. It helps identify the patient that should be evacuated as soon as possible and within a maximum of 2 hours to save life, limb, or eyesight[5], prevent serious illness complications, or avoid permanent disability. This is done as per a priority scale[6]:

- Priority I - URGENT is assigned to emergency cases that should be evacuated as soon as possible. Such casualty requires evacuation within a maximum of 2 hours. Evacuation is required in order to save life, limb, or eyesight and is used to prevent complications of severe illness or to avoid permanent disability

- Priority IA-URGENT-SURG is assigned to patients who must receive surgical intervention far forward to save lives and 


\section{Table 1. Advantages of effective CASEVAC}

\begin{tabular}{ll}
\hline Advantage & Rationale \\
Speed & $\begin{array}{l}\text { The "Golden Hour" [27] of resuscitation \& "Platinum Ten "[28] principles can be better utilized by rapid and safe air } \\
\text { transport of the casualty. The value of rapid evacuation to a designated trauma center has been well demonstrated in } \\
\text { modern medicine }\end{array}$ \\
$\begin{array}{l}\text { Range } \\
\text { Trafficability }\end{array}$ & $\begin{array}{l}\text { Rotor-wing aircraft can pick up patients in relatively inaccessible areas and transport them quickly and safely. The prerequisite } \\
\text { of minimal landing requirements provide for this feature }\end{array}$ \\
Flexibility & $\begin{array}{l}\text { A casualty can be airlifted quickly to that medical installation where appropriate specialized care may be available, thereby } \\
\text { bypassing unnecessary delays }\end{array}$ \\
Comfort and Morale & $\begin{array}{l}\text { Because of the speed and comfort of the flight, the soldier knows that if injured, he can be transported to the appropriate } \\
\text { medical treatment facility quickly and in stable condition[4]. }\end{array}$ \\
Economy of Resources & Because one large hospital is able to accommodate several battle areas, fewer facilities only needs to be set up
\end{tabular}

stabilize for further evacuation.

- Priority II-PRIORITY is assigned to sick and wounded personnel requiring prompt medical care. This precedence is used when

(a) the individual should be evacuated within 4 hours, or his medical condition could deteriorate to such a degree that he will become URGENT precedence, or

(b) requirements for special treatment are not available locally, or

(c) will suffer unnecessary pain or disability.

- Priority III-ROUTINE is assigned to sick and wounded personnel requiring evacuation but whose condition is not expected to deteriorate significantly. The sick and wounded in this category should be evacuated within 24 hours.

- Priority IV-CONVENIENCE is assigned to patients for whom aeromedical evacuation is a matter of medical convenience rather than necessity.

- Priority V-Cas evac by road (stable patients/minor injuries).

\section{Goals}

Safe practice for the aeromedical patient involves:

a) Stabilizing the patient for flight.

b) A thorough medical evaluation and narrative summary.

c) A plan of care that includes consideration of the patient's condition in relation to the "stresses of flight."

d) To prepare the patient's medical record, investigations and X-rays for travel.

e) To prepare and instruct the patient about travel (if conscious).

f) Briefing of the pilot by the medical team on altitude \& temperature requirements during transit.

\section{Oxygen Equipment Use in General Aviation Operations}

Since oxygen is an essential component in any air journey, a basic knowledge of oxygen equipment can be critical whether we are flying a commercial, commuter, general aviation aircraft or doing a CASEVAC. This equipment is the first line of defence against the potentially lethal effects of hypoxia and carbon monoxide poisoning. It is thus imperative that all aboard the aircraft-crew members and passengers know how to use this life-saving equipment safely and efficiently.

\section{General precautions}

The following points describe operational precautions to use with all types of oxygen systems. The basic principles and practices include[7]:

1. Keep your equipment clean. The interaction of oil-based products and oxygen creates a fire hazard. Additionally, oil attracts dirt particles, and these dirt particles can contaminate storage containers, regulators, masks, and valves. For cleaning instructions, check with the manufacturer's guide.

2. Protect your oxygen mask from direct sunlight and dust. Store in proper containers.

3. Inspect oxygen storage containers. Ensure that they are securely fastened in the aircraft, as turbulence or abrupt changes in attitude can cause them to come loose. Proper inspections are essential, so your oxygen equipment should be inspected regularly at an authorized Federal Aviation Administration inspection station.

4. No smoking! Oxygen is highly flammable. Do not allow anyone to smoke around the oxygen equipment that is being used. Likewise, no one should smoke around oxygen equipment that is being recharged. Ensure that the aircraft is correctly grounded before loading oxygen.

5. Mix and match components with caution. When interchanging oxygen systems components, ensure compatibility of the components- storage containers, regulators, and masks.

\section{Storage Systems}

Apart from the medical-grade oxygen carried by medical teams, there is always additional oxygen available in the flight should the oxygen run out. The quantity of the same is subject to the flight and local regulations. Oxygen is stored in the aircraft as a gas, liquid, or solid.

1. Gaseous aviator's breathing oxygen (ABO).

Storing oxygen as gas has the significant advantage of being more economical. It can be stored in high-pressure (1800-2200 psi) containers or low-pressure (400-450 psi) containers. The major disadvantage is the weight and bulk of the storage containers, which may become an issue in smaller aircraft. Oxygen for breathing in the aircraft must meet specific standards to ensure that it is safe to be taken to Altitude. Only aviator's-grade breathing oxygen meets this specification. Neither medical-grade nor industrial-gra- 
de oxygen is safe to substitute because they do not meet the same stringent standards as $A B O$.

2. Liquid aviators are breathing Oxygen (LOX).

Oxygen can be serviced to the aircraft in a liquid state. The advantage of LOX is that it has a 900 to 1 expansion ratio. In other words, one litre of LOX will expand into 900 gaseous litres of $A B O$. This will afford a 3 to 1 space and 5 to 1 weight savings over gaseous $A B O$. The major disadvantages are that LOX is stored at its critical temperature of minus $197^{\circ} \mathrm{F}$ and its volatile nature when it comes in contact with petroleum products. If LOX comes in contact with exposed skin, severe frostbite may occur.

3. Sodium chlorate candles (solid-state oxygen).

Sodium chlorate is a chemical that, when heated to $350^{\circ}$ $\mathrm{F}$, will thermally decompose and release oxygen. Sodium chlorate candles have the advantage of saving weight and space over $A B O$ because it provides a 600 to 1 expansion ratio. The major disadvantage is that once the chemical reaction (the candle is activated) has started, it can't be easily stopped. Additionally, the candle produces a great deal of heat, and precautions must be taken to avoid a fire hazard.

4. Molecular sieve oxygen generators (MSOG).

The air that we breathe contains $21 \%$ oxygen, and the remainder is inert gases that play no significant physiological role in the body. MSOGs take ambient air and separate oxygen from inert gases, using that to supply oxygen to the aircraft. The military has used this system for many years and medical patients who need a portable oxygen system. Civil aviation has not embraced MSOG, but it may be more in vogue in future aircraft.

\section{Stressors of flight/special implications}

Divisions of the atmosphere have a different influence on the physiological effects on the human body (Table 1)[8].

Considerations and orders given for a aero-med evacuation are based on the "stresses of flight[9]." Stresses involve the physiological principles encountered as one travels to higher Altitude. One factor that tends to make jeopardize travel is hypoxia. What makes it so dangerous is its insidious onset. Any body who flies above 12,000 feet in an unpressurized aircraft without supplemental oxygen is a potential hypoxia case. Common types of hypoxia are described in Table 2.

\section{Gas Laws and alteration of physiology}

1. Dalton proved the decreased partial pressure of a gas at increased Altitude[10]. As one travels higher, the amount of available oxygen is reduced. This principle presents the problem of hypoxia for every flyer. Patients who smoke and those who have emphysema are affected by the condition of hypoxic hypoxia[11]. Patients with anaemic conditions and those with sickle cell anaemia are affected by hyphemia hypoxia[4],[12]. Patients with sickle cell anaemia have suffered cell sickling when over 4,000 feet altitude[13]. Usually, the altitude restriction recommended for both unpressurized and pressurized aircraft is a maximum of $8,000 \mathrm{ft}$. Transport aircraft have a cruising height of 25,000 to 30,000 feet[14] with a cabin altitude maximum of 8,000 feet. At $8,000 \mathrm{ft}$, partial pressure of inspired oxygen is around 108 $\mathrm{mm} \mathrm{Hg}$ which is adequate to maintain an oxygen saturation of over $90 \%$ in a healthy individual. Patients in shock or suffering from congestive heart failure are affected by stagnant hypoxia[15]. Patients who abuse drugs and alcohol are affected by histotoxic hypoxia[16]. To protect patients who are at risk from hypoxic effects, oxygen should be ordered for inflight use, and a lower cabin altitude should be used if indicated. When a field elevation altitude is ordered, the aeroplane will fly lower and slower.

2. Boyle's law says that, as barometric pressure decreases, the volume of gas increases when at a constant temperature[10]. Patients with conditions in which trapped gas is present need to be protected from gas expansion. A change in sea level to an Altitude of 8,000 feet will expand the volume of trapped gas by $20 \%$. Patients with gastrointestinal tract injuries suffer distension and discomfort. Individuals with ulcer, diverticulitis, colostomy and postoperative abdominal patients are more likely to suffer from trapped gas in the gastrointestinal tract. Pneumothorax or postoperative chest surgery patients could suffer a mediastinal shift when trapped gas expands. When tension pneumothorax is suspected, immediate tension relief (Needle thoracostomy) using a wide bore needle is indicated. Hemo-thorax will require intercostal drainage (ICD) placement in the 4 - fifth $^{\text {th }}$ intercostal space[17]. Expansion of trapped gas in eye injuries with globe perforation can cause extrusion of the lens or vitreous. Expansion of air in the cuff of the endotracheal tube can also cause damage to the tracheal epithelia.

3. Charles law describes the response of gas temperature to

\begin{tabular}{|c|c|c|c|}
\hline Zones & Altitudes & Pressure & Characteristics \\
\hline Physiological Efficient Zone & Sea Level - 12,500 feet & $760-523 \mathrm{~mm} / \mathrm{Hg}$ & $\begin{array}{l}\text { Generally, the body has adapted to operate in the lower regions of } \\
\text { this zone. Minor trapped gas problems (ears, sinus, and Gl tract.) } \\
\text { occur in the lower region of this zone while shortness of breath, } \\
\text { dizziness, headaches and fatigue in the upper region if exposure } \\
\text { too long }\end{array}$ \\
\hline Physiological Deficient Zone & $12,500-50,000$ feet & $523-87 \mathrm{~mm} / \mathrm{Hg}$ & $\begin{array}{l}\text { The majority of flying is conducted in this zone. The lack of } \\
\text { atmospheric pressure causes major physiological problems...hypoxia } \\
\text { and decompression sickness }\end{array}$ \\
\hline Space Equivalent Zone & $50,000 \mathrm{ft}$ - 1000 miles & $87-0 \mathrm{~mm} / \mathrm{Hg}$ & $\begin{array}{l}\text { This environment is very hostile to humans. "Armstrong's line" is at } \\
63,000 \text { feet and any unprotected exposure above this level causes } \\
\text { body fluids to boil. There is a need for a sealed cabin and thrusters } \\
\text { on the air/space craft }\end{array}$ \\
\hline
\end{tabular}




\section{Table 3. Types of hypoxia}

\begin{tabular}{|c|c|c|}
\hline Location of impediment & Common name & Explanation \\
\hline Lungs & $\begin{array}{l}\text { Hypoxic } \\
\text { Hypoxia }\end{array}$ & $\begin{array}{l}\text { Any condition that interrupts the flow of } \mathrm{O}_{2} \text { into the lungs. This is the type of hypoxia encountered } \\
\text { at Altitude due to reducing the partial pressure of } \mathrm{O}_{2}\end{array}$ \\
\hline Blood & $\begin{array}{l}\text { Hypemic } \\
\text { Hypoxia }\end{array}$ & $\begin{array}{l}\text { Any condition that interferes with the ability of the blood to carry oxygen. Anaemia and carbon } \\
\text { monoxide poisoning are two conditions that can keep the } \mathrm{O}_{2} \text { from attaching to the haemoglobin } \\
\text { within the red blood cell }\end{array}$ \\
\hline Blood transport & $\begin{array}{l}\text { Stagnant } \\
\text { Hypoxia }\end{array}$ & $\begin{array}{l}\text { Any condition that interferes with the normal circulation of the blood arriving in the cells. Heart } \\
\text { failure, shock, and positive } G \text { force along the Z-axis will bring about this condition }\end{array}$ \\
\hline Cell & $\begin{array}{l}\text { Histotoxic } \\
\text { Hypoxia }\end{array}$ & $\begin{array}{l}\text { Any condition that interferes with the normal utilization of } \mathrm{O}_{2} \text { in the cell } \\
\text { Alcohol, narcotics and cyanide all can interfere with the cell's ability to use the oxygen in support } \\
\text { of metabolism }\end{array}$ \\
\hline
\end{tabular}

pressure changes[10]. It is cold at Altitude, since the pressure at Altitude is less, so the temperature is less. Temperature decreases with increasing Altitude and is approximately -57 $\operatorname{deg} C$ at the typical flight altitude at 35,000 feet[18]. Aircraft have varying abilities to maintain cabin temperature. One spot in the plane is hot, while another is quite chilly. Changes in oxygen consumption rate and metabolic rate are influenced by temperature. Patients with hypothermic and hyperthermic conditions require special consideration. For burn victims, the aircraft cabin should be heated above the normal to protect the patient. Decreased humidity is another stressor. Cool air loses its ability to hold moisture. After flying two hours on an AN-32 flight, the humidity may drop to $5 \%$ and after 4 hours to $1 \%$. Patients with respiratory conditions are uncomfortable in 5\% to $10 \%$ humidity; therefore, all oxygen administered on the plane needs to be humidified[19]. (Oxygen has not been shown to have any effect on the sensation of breath-lessness in non-hypoxaemic patients. Patients who cannot take liquids every hour should have intravenous fluids for flight.

4. The effect of Henry's law and Graham's Law is mentioned in Table 3 compared to the above laws[8].

\section{Effects of the ambient environment}

1. Aircraft engine noise creates auditory fatigue[20]. The importance of on-board communication skills plays a vital role. Supra-normal noise also creates health care problems in communication and in vital sign monitoring in which auscultation is required. Noise also precludes appreciation of auditory alarms of ventilators and monitors, necessitating continuous eye contact with the patient and equipment (Table 4). Noise peak is during take-off, which means exposure on a standard evac mission from the periphery to a tertiary centre could go up to 4-6 times a day, starting from periphery to a tertiary centre. Noise in a helicopter can approach 90 decibels[21] which is approx. 2,000 times louder than the heart/breath sounds audible by a stethoscope. Ear protection should be provided to all passengers aboard military aircraft to protect hearing and minimize this stress. Mi 17 is known to cause transient deafness if ear protection is not done.

2. Acceleration, deceleration, and vibration are also discomforting for flyers. In a supine patient, gravitational forces ( $G$ Forces) during acceleration as in take-off will act in the horizontal axis and result in blood pooling in the lower extremities if loaded head first[22]. Healthy humans will be able to mount a compensatory sympathetic response. A patient with labile hemodynamics or impaired autonomic function could have a fall in cardiac output. A patient with a head injury will have an increased ICP during "take off" if positioned feet first. The G Force will act in the opposite direction while landing[23]. Patient positioning thus requires deliberation. Vibration can interfere with graphic displays of electrocardiogram, pulse oximetry and ventilatory parameters by causing artifacts. These factors along with the others previously mentioned combine to make up the "stresses of flight."

\section{Red flag patient conditions wrt Altitude}

Protection of patients by briefing the pilot for an altitude restriction $(3,000 \mathrm{ft}$ for non-pressurized and $\max 8,000 \mathrm{ft}$ for pressurized aircraft) should be considered when the patient diagnosis is one of the following. However, in high altitude evacuations, this aspect is not possible[14]. So the patient has to be pre oxygenated[24] on $100 \% \mathrm{O}_{2}$ from the beginning of the flight.

a) Air embolism.

b) Tuberculosis cavities.

c) Cardiac conditions with angina or post-myocardial infarction less than 07 days.

d) Eye injuries with air in the globe.

e) Anaemia with haemoglobin below $7 \mathrm{~g} / 100 \mathrm{ml}$.

f) Free air in any body cavity, such as pneumothorax or gangrene.

g) Respiratory distress in adults, children, and infants.

h) Aneurysm. Also, it may be necessary for aneurysm patients to ask for no remain overnight stops and nonstop flight to the destination.

i) Diffused interstitial fibrosis.

j) Pericardial effusions or pleural effusion.

k) Otitis media or condition with fluid in the ear.

l) Sinusitis.

\section{Special situations encountered in air transport}

Including an altitude, restriction may add flying time and possible increased turbulence during the flight. This needs to be 


\section{Table 4. Gas Laws and application in aviation}

\begin{tabular}{|c|c|c|}
\hline Gas Law & Explanation & Aviation application \\
\hline $\begin{array}{l}\text { Dalton's Law } \\
\text { PT }=\text { P1 }+ \text { P2 }+\ldots \text { PN }\end{array}$ & $\begin{array}{l}\text { The total pressure of a mixture of gas is equal } \\
\text { to the sum of the partial pressure of each gas } \\
\text { in the mixture }\end{array}$ & $\begin{array}{l}\text { Hypoxia } \\
\text { Explains how ascent to Altitude reduces the total atmospheric } \\
\text { pressure and each of the partial pressures associated with the total } \\
\text { atmospheric pressure }\end{array}$ \\
\hline Boyle's Law $\frac{P 1}{P 2}=\frac{V 2}{V 1}$ & $\begin{array}{l}\text { A volume of a gas is inversely proportional } \\
\text { to the pressure to which it is subjected, the } \\
\text { temperature remaining constant }\end{array}$ & $\begin{array}{l}\text { Trapped Gas } \\
\text { Explains how pressure change allows the gas to expand and contract } \\
\text { in body cavities (ears, sinuses, and Gl tract) with increasing and } \\
\text { decreasing Altitude }\end{array}$ \\
\hline Henry's Law $\frac{P 1}{P 2}=\frac{A 1}{A 2}$ & $\begin{array}{l}\text { The amount of gas dissolved in the solution } \\
\text { varies directly with the pressure of that gas } \\
\text { over the solution }\end{array}$ & $\begin{array}{l}\text { Decompression sickness } \\
\text { Explains why nitrogen in the body comes out of solution forming } \\
\text { bubbles that cause altitude decompression sickness. As altitude } \\
\text { increases, pressure decreases and nitrogen will attempt to leave the } \\
\text { body and equalize with the surrounding environment. If the pressure } \\
\text { change is too rapid, the excess nitrogen may form a bubble(s) }\end{array}$ \\
\hline $\begin{array}{l}\text { Graham's Law } \\
\text { Law of gaseous diffusion }\end{array}$ & $\begin{array}{l}\text { A gas will diffuse from an area of high } \\
\text { concentration to an area of low concentration }\end{array}$ & $\begin{array}{l}\text { Transfer of Gas in body } \\
\text { Explains the transfer of gases between the atmosphere and the lungs, } \\
\text { the lungs and blood, and the blood and the cell }\end{array}$ \\
\hline Charles' Law P1T2 = P1T1 & $\begin{array}{l}\text { The pressure of a gas is directly proportional to } \\
\text { its temperature }\end{array}$ & $\begin{array}{l}\text { This gas law has no physiological bearing since that body temperature } \\
\text { is a constant } 98.6 \text { degrees Fahrenheit }\end{array}$ \\
\hline
\end{tabular}

\section{Table 5. Primary sources of noise in aircraft}

Squeaks \& Rattles

Exhaust

Propellers

Ventilation system

Air turbulence around fuselage
Squeaks and rattles may be remedied by welding rather than riveting. However, there still would not be a difference in sound intensity after it was done

Engine exhaust can be muffled, but this adds weight to the aircraft

Propeller driven aircraft predominately produce low-frequency noise, with the most intense portion of the noise at the pilot's position. The higher speed of propeller rotation will result in a slight upward shift in the predominant frequency range. Prop noise ranges from 89 to $113 \mathrm{~dB}$ with an average of $106 \mathrm{~dB}$

In light aircraft tested, ventilation noise turned out to be as noisy as all other sources put together. However, if manufactures quieted the system, it would only decrease sound by $3 \mathrm{~dB}$

Another source of noise in aircraft is airflow or air turbulence around the fuselage. This is vividly demonstrated when the engines quit during flight and noise is still heard around the aircraft considered when planning air transport. There are other special conditions requiring consideration. If the patient has wired jaws, there must be a quick-release mechanism or wire cutters. The physician/surgeon should explain to the flight medical crew concerning how to release or cut the wires and how to support the jaw afterwards.

When the patient has a tracheostomy, the tube should be changed before a flight. The tracheostomy should be postoperative by at least $24 \mathrm{~h}$. A spare sterilized tracheostomy tube of the appropriate size should be sent with the patient. Humidity and suction should be ordered. The flight nurse needs to know the type of tracheostomy cuff the patient has. A soft cuff is preferred.

Orthopaedic casts should be dry. There are no cast cutters on the plane. If the patient swells, as with a fresh fracture, the cast should be split/ bivalved prior to flight to permit swelling without vascular insult. Travelling with a wet cast is dangerous, as the cast is likely to get dented and dinged. A window in the cast is desirable when vascular injuries are present[4].

Loss of intravenous access, accidental extubation \& bleeding due to vibration/turbulence is also common occurrences.
During winching, all these situations aggravate further. The difficulty in monitoring the patient during the process makes the situation more complicated. When the patient is being winched, ensure that the patient's safety harness is fastened securely and that monitors are also attached to the scoop or the PTU. If the patient is being winched in a cold zone, ensure the patient is kept warm.

Backflow of blood through iv tubing because of pressure difference is a common occurrence and should be watched for. In mechanically ventilated patients, the concerns are the following[4]:

a) Increased incidence of ventilator-induced lung injury.

b) Airway obstruction with mucus plugs due to decreased humidity.

\section{Unique issues inpatient care during casevac}

The most common problems encountered during CASEVAC are[4]:

a) Difficulty in the manual measurement of pulse and blood 
pressure due to noise/vibration.

b) Inaccurate reading of automatic non-invasive blood pressure.

c) Inaccurate delivery of tidal volume in mechanically ventilated patients requiring frequent troubleshooting.

d) Injury to medical personnel while using glass vials on a turbulent aircraft.

e) Electromagnetic interference between avionics and monitors can cause artefacts and erroneous reading. Hence military-grade equipment that has been tested for avionic interference and vibration compensation should only be used.

f) Electrical coupling of medical equipment should be ensured with the aircraft electrical systems (which may occasionally vary, depending on country of manufacture).

g) During winching, patient cannot be monitored.

h) Difficulty in hearing audio alarms.

i) Functional difficulties include.

i. Exhaustion of oxygen supply.

ii. Difficulty in performing procedures.

iii. Disposal of patient body fluids and excreta.

\section{Contraindications}

There are no absolute contraindications to CASEVAC. Important relative contraindications to non-emergent CASEVAC are:

a) Pneumothorax, unless decompressed by a chest tube.

b) Laparotomy or thoracotomy within the previous one week.

c) Bowel obstruction from any source (commonly postoperative).

d) Eye surgery within previous 7-14 days.

e) Uncontrolled dysrhythmias.

f) Acute Myocardial Infarction without reperfusion.

g) Congestive heart failure with acute pulmonary oedema.

h) Haemorrhagic cerebrovascular accident within the previous week.

i) Severe uncorrected anaemia (haemoglobin $<7.0 \mathrm{~g} / \mathrm{dl}$ ).

j) Spinal injury unless immobilized.

k) Acute blood loss with a haematocrit below 30\%.

l) Acute psychosis (without physical or pharmacological restraint).

\section{Checklist for patient preparation}

\section{The PRICE Check}

Prior to every flight, the pilot should perform the "PRICE" check on the oxygen equipment. The acronym PRICE is a checklist memory-jogger that helps pilots and crewmembers inspect oxygen equipment.

1. Pressure - ensure that there is enough oxygen pressure and quantity to complete the flight.

2. Regulator - inspect the oxygen regulator for proper function. If you are using a continuous-flow system, make sure the outlet assembly and plug-in coupling are compatible.

3. Indicator - most oxygen delivery systems indicate oxygen flow by use of flow indicators. Flow indicators may be located on the regulator or within the oxygen delivery tube. Don the mask and check the flow indicator to assure a steady flow of oxygen.
4. Connections - ensure that all connections are secured. This includes oxygen lines, plug-in coupling, and the mask.

5. Emergency - have oxygen equipment in the aircraft ready to use for those emergencies that call for oxygen (hypoxia, decompression sickness, smoke and fumes, and rapid decompressions.) This step should include briefing passengers on the location of oxygen and its proper use.

\section{Airway management}

a) Continuous monitoring of the ETT cuff pressure to prevent air expansion.

b) Use tube fixator for endotracheal tube.

c) Humidified supplemental oxygen to maintain saturation $>$ $90 \%$.

d) All electronic machines have batteries fully charged and with backup and IATA approved.

\section{Head injuries}

a) Careful positioning of the patient to avoid a rise in intracranial pressure (ICP).

b) Use of eye pads/ointment/artificial tears in an unconscious patient.

\section{Maxillofacial injuries}

a) Quick-release mechanism for wired jaws or easy access to wire cutters.

\section{Chest injuries}

a) Ensure functional status of intercostal drainage (ICD) tube.

b) Never clamp the ICDs in flight.

\section{Abdominal injuries}

a) Ensure all drainage tubes are unclamped or on continuous suction.

b) Abdominal binder application in cases of open abdominal trauma.

c) Broad-spectrum antibiotics \& Analgesics to be started before transport of a patient.

d) If bowel loops protrude outside the abdominal cavity, use saline-soaked gauze piece to cover the wound

\section{Orthopaedic injuries}

a) Avoid the use of pneumatic splints for they are known to cause vascular compromise.

b) Ensure optimal stability of the fracture segments.

\section{Haemorrhagic shock}

a) Ensure minimum haemoglobin of $7.0 \mathrm{gm} / \mathrm{dl}[4]-8.0 \mathrm{gm} /$ dl[25].

b) Likely to have increased IV fluid requirements in flight.

c) Availability of pressure bags.

\section{Burn injuries}

a) Ensure escharotomies for full-thickness circumferential burns.

\section{Hypothermia}

a) Replace wet clothing with dry clothing.

b) Apply ultra-light heat blanket / ready-heat blanket from the Hypothermia Prevention and Management Kit (HPMK) to 
the patient torso and cover the casuality with the Heat Reflective Shell (HRS).

\section{Liaison with aircrew}

a) Cabin altitude.

b) Weather en-route.

c) Inside cabin temperature should be maintained between 22-24 C.

\section{Civilian approaches to the assignment of evacuation priority}

The assignment of evacuation priorities, by its very nature is subjective. To bring objectivity to the determination of the need for helicopter evacuation to a higher centre, civilian emergency medical systems have adopted the use of triage scoring systems. The civilian approach needs to be understood by military anesthesiologists \& physicians because a modification may apply to military medical evacuation.

The CRAMS scale is one such and was developed by S. P. Gormican in 1982 and modified by T. P. Clemmer in 1985. It is a simple and easy scale to remember, with the acronym letters representing circulation, respiration, abdomen, motor, and speech. The CRAMS scale score will allow for objective assessment for evacuation[26].

\section{Circulation}

1. Score 2: Normal capillary refill and blood pressure $>100$ $\mathrm{mm} \mathrm{Hg}$ systolic.

2. Score 1: Delayed capillary refill or blood pressure 85-99 mm Hg systolic.

3. Score 0: No capillary refill or blood pressure $<85 \mathrm{~mm} \mathrm{Hg}$ systolic.

\section{Respiration}

1. Score 2: Normal.

2. Score 1: Abnormal (laboured, shallow, or rate $>35 \mathrm{bpm}$ ).

3. Score 0: Absent.

\section{Abdomen}

1. Score 2: Abdomen and thorax not tender.

2. Score 1: Abdomen and thorax tender.

3. Score 0: Abdomen rigid, thorax flail, or deep penetrating injury to either chest or abdomen.

\section{Motor}

1. Score 2: Normal (obeys commands).

2. Score 1: Response only to pain, no posturing.

3. Score 0: Postures or no response.

\section{Speech}

1. Score 2: Normal (oriented).

2. Score 1: Confused or inappropriate.

3. Score 0: Unintelligible or no sounds.

\section{The medical equipment}

These are the essential medical equipment needed in trans- porting the patients (in) with aircraft. Every personnel on the team must be familiar with this equipment:

a. Patient transfer unit (PTU) fitted with a multimode ventilator.

b. Resuscitation Set + oxygen

c. Blood gas analyzer.

d. Ambu Bag.

e. Intubation Set.

f. Suction Apparatus.

g. Sphygmomanometer.

h. Infusion \& Infusion Set.

i. i.v. Catheter \& CVP Set.

j. Cricothyrotomy kit (e.g. Cooks Critical care: Melker's Cricothyrotomy Kit).

k. LMA (or other Supraglottic devices).

I. NIV (especially in fixed-wing aircraft - for judicious use in non-intubated patients).

m. Bandages.

n. Fixation Tools \& Splints.

o. Vacuum Mattress.

p. Injection Set.

q. Minor Surgery Set.

r. Gastric Tubes.

s. Portable ECG \& Defibrillator.

t. Oxygen cylinders.

u. Three pin adapters (Electrical coupling of medical equipment with the aircraft electrical systems (which may occasionally vary, depending on country of manufacture)).

Drugs and consumables need to be stored in compact containers. Essential medical equipment has to be kept secured but still within reach. Every crewmember must know exactly what is on board and where it is, so (as) not to be dependent on other crewmembers in an emergency.

\section{Points for evacuating doctors}

Apart from the above details, the evacuating team should be well trained to / aware of:

a) Immediately demand a helicopter for evac through proper channel.

b) How to prepare the Helipad for evac.

a. Air socks for wind direction.

b. Smoke candles for landing.

c. Helipad protection.

c) Air certified cylinders - Provision for Aviation $\mathrm{O}_{2}$ Cylinders (as differentiated from the aviation crew oxygen supplies)

d) Should the oxygen cylinder exhaust on board, how to demand and use the inflight oxygen.

e) Since many battle theatres are already at high Altitude, evac from those zones should warrant extra care and precautions.

f) Foresee peak evacuation period and be prepared.

g) Casualties travel better before surgery than immediately after surgery.

h) Proper triage is essential while evacuating mass casualties.

i) To get first-hand experience using oxygen equipment, it is highly recommended that all trauma/evacuation team members, especially those operating their aircraft at altitu- 
des where oxygen is required, get additional training in an altitude chamber.

\section{Conclusion}

Optimal pre-hospital care for the injured patient is controversial. The lack of solid evidence and the methodological limitations inherent in most analyses make any definitive recommendations open to criticism[47]. In addition, the interpretation of published evidence is complicated by the significant heterogeneity in study design, patient populations, outcomes of interest and variability in the type of interventions performed in the pre-hospital setting. Even the most extensive population-based comparison of pre-hospital systems demonstrated significant variability in early mortality among patients treated under similar pre-hospital programs but in different countries, underscoring the high degree of variability introduced by other processes of care in any study of pre-hospital interventions[14]. Efforts to dichotomize pre-hospital systems into either ALS type or BLS type do not sufficiently take into account this heterogeneity[1].

Sound knowledge of the various nuances of air evacuation is mandatory for the planning and execution of a CASEVAC. Using the framework mentioned above, each medical care sector can prepare its strategy as per its location and staging facilities.

\section{Main points}

1. CASEVAC should be carried out as per standard checklists and by a highly specialized team of health care professionals.

2. Given that the guidelines are non-uniformly structured, this article endeavours to help care providers plan and execute effective care before and during CASEVAC.

3. The experience of senior medical professionals in the Indian Army and UN has contributed to this article in medical transfers during war and peace.

4. A review of pertinent literature on the same subject has been incorporated into the manuscript.

\section{References}

1. Haas B, Nathens AB. Pro/con debate: is the scoop and run approach the best approach to trauma services organization? [Internet]. Vol. 12, Critical care (London, England). BioMed Central; 2008. p. 224. Available from: http://ccforum.biomedcentral.com/articles/10.1186/cc6980 https://doi.org/10.1186/ cc6980

2. Sarkar R, Mohapatra S. Accident of a civil passenger aircraft at a military airfield: The Casevac experience. Indian J Aerosp Med [Internet]. 2020 Oct 3;63(2):96. Available from: https:// indjaerospacemed.com/accident-of-a-civil-passenger-aircraft-at-amilitary-airfield-the-casevac-experience/ https://doi.org/10.25259/ IJASM_7_2019

3. Sasidharan S, Singh V, Dhillon H, Babitha M. Patient isolation pods for the evacuation of COVID-19 infected patients - Is this the answer? [Internet]. Vol. 36, Journal of Anaesthesiology Clinical Pharmacology. Wolters Kluwer Medknow Publications; 2020 [cited 2021 Feb 12]. p. S152-5. https://doi.org/10.4103/joacp. JOACP_344_20

4. Joshi MC, Sharma RM. Aero-medical considerations in casualty air evacuation (CASAEVAC). Med J Armed Forces India [Internet]. 2010;66(1):63-5. https://doi.org/10.1016/\$0377-1237(10)800978

5. Clasper JC, Midwinter MJ. Forward surgery. [Internet]. Vol. 153, Journal of the Royal Army Medical Corps. British Medical Journal Publishing Group; 2007. p. 149-51. Available from: https://militaryhealth.bmj.com/content/153/3/149 https://doi.org/10.1136/ jramc-153-03-01

6. Evacuation Request Procedure [Internet]. Available from: http:// www.medtrng.com/evacuation_request_procedure.htm

7. OXYGEN EQUIPMENT. Med J Aust. 1966;1(7):280-280. https:// doi.org/10.5694/j.1326-5377.1966.tb19722.x

8. Federal Aviation Administration. Aviation Physiology [Internet] 2005. Available from: https://www.faa.gov/pilots/training/airman_education/media/IntroAviationPhys.pdf

9. Blumen IJ, Rinnert KJ. Altitude physiology and the stresses of flight. Air Med J. 1995 Apr 1;14(2):87-100. https://doi. org/10.1016/S1067-991X(95)90102-7

10. Chandan G, Cascella M. Gas Laws and Clinical Application [Internet]. StatPearls. StatPearls Publishing; 2019

11. Hypoxic Hypoxia - an overview / ScienceDirect Topics [Internet]. [cited 2021 Feb 12]. Available from: https://www.sciencedirect. com/topics/medicine-and-dentistry/hypoxic-hypoxia

12. Hansen PJ. Safe practice for our aeromedical evacuation patients Mil Med [Internet]. 1987;152(6):281-3. Available from: https:// www.google.com/search?q=Safe+Practice+for+Our+Aeromedic al+Evacuation+Patients\&rlz=1C1CHBD_enIN922IN922\&oq=Safe +Practice+for+Our+Aeromedical+Evacuation+Patients\&aqs=chro me..69i57\&sourceid=chrome\&ie=UTF-8 https://doi.org/10.1093/ milmed/152.6.281

13. Claster S, Godwin MJ, Embury SH. Risk of altitude exposure in sickle cell disease. West J Med [Internet]. 1981 Nov;135(5):364-7.

14. Cabin Cruising Altitudes for Regular Transport Aircraft.; Available from: www.asma.org

15. Bonanno FG. Clinical pathology of the shock syndromes. In: Journal of Emergencies, Trauma and Shock [Internet]. Wolters Kluwer - Medknow Publications; 2011. p. 233-43. https://doi. org/10.4103/0974-2700.82211

16. Wang SM, Wu R. The double danger of ethanol and hypoxia: their effects on a hepatoma cell line. Int J Clin Exp Pathol [Internet]. 2009 [cited 2021 Feb 12];2(2):182-9. Available from: http:// www.ncbi.nlm.nih.gov/pubmed/19079654

17. Foernges LG. Chest tube. In: Pediatric Surgery: Diagnosis and Treatment [Internet]. Springer International Publishing; 2014 [cited 2021 Feb 12]. p. 403-6. Available from: https://www.ncbi. nlm.nih.gov/books/NBK459199/ https://doi.org/10.1007/978-3319-04340-1_76

18. PHAK Chapter 4. In: Federal Aviation Administration.

19. O'Driscoll BR, Howard LS, Davison AG. BTS guideline for emergency oxygen use in adult patients. Thorax [Internet]. 2008 Oct 1;63(SUPPL. 6):vi1-68. Available from: http://thorax.bmj.com/ https://doi.org/10.1136/thx.2008.102947

20. HEARING AND NOISE IN AVIATION HEARING.

21. Küpper TEAH, Steffgen J, Jansing P. Noise Exposure During Alpine Helicopter Rescue Operations. Ann Occup Hyg [Internet]. 
2004 May 1;48(5):475-81. Available from: https://academic.oup. com/annweh/article/48/5/475/229189/Noise-Exposure-DuringAlpine-Helicopter-Rescue

22. What are g-forces and are they caused by gravity? - NPL [Internet]. Available from: https://www.npl.co.uk/resources/q-a/are-gforces-caused-by-gravity

23. What Goes Up Must Come Down.

24. Nimmagadda U, Salem MR, Crystal GJ. Preoxygenation. Anesth Analg [Internet]. 2017 Feb 1;124(2):507-17. Available from: http://journals.Iww.com/00000539-201702000-00022 https:// doi.org/10.1213/ANE.0000000000001589

25. US Army SMOG 2020 Guidelines - Google Search [Internet]. Available from: https://www.google.com/search?q=US+Army+S MOG+2020+Guidelines\&rlz=1C1CHBD_enIN922IN922\&oq=US+
Army+SMOG+2020+Guidelines\&aqs=chrome..69i57.5471142j0j $7 \&$ sourceid $=$ chrome\&ie $=$ UTF- 8

26. Clemmer TP, Orme JF, Thomas F, Brooks KA. Prospective evaluation of the CRAMS scale for triaging major trauma. J Trauma - Inj Infect Crit Care [Internet]. 1985;25(3):188-91. Available from: https://pubmed.ncbi.nlm.nih.gov/3981668/ https://doi. org/10.1097/00005373-198503000-00003

27. Lerner EB, Moscati RM. The Golden Hour: Scientific Fact or Medical "Urban Legend" ? Acad Emerg Med [Internet]. $2001 \mathrm{Jul} 1$ [cited 2021 Feb 12];8(7):758-60. https://doi. org/10.1111/j.1553-2712.2001.tb00201.x

28. The Platinum Ten The final countdown in the moments following a serious motor vehicle accident What is meant by the "Platinum Ten"? 